\title{
Appraising New Technologies for Learning: A Framework for Development
}

\author{
David Boud and Michael Prosser, Sydney, Australia
}

\begin{abstract}
s
The paper discusses a framework for the analysis of learning designs using new technologies. It takes a learner-centred view derived from literature in higher, professional and adult education. The process of developing guidelines for applying this framework to particular learning activities is outlined and the strengths and limitations of this approach considered.
\end{abstract}

Evaluation des nouvelles technologies pour l'enseignement

L'article discute d'un cadre pour l'analyse de schémas d'enseignement faisant usage des nouvelles technologies. Il prend en compte un enseignement centré sur l'apprenant à partir d'articles et de livres sur l'éducation supérieure, professionnelle et des adultes. Le processus de développement des lignes directrices pour l'application de ce cadre à des activités d'enseignement particuliers est mis en valeur et les forces et les limitations de cette approche sont prises en considération.

Bewertung neuer Lerntechnologien: Grundlagen zur Weiterentwicklung

In diesem Artikel werden Grundlagen zur Analyse von Lernformen besprochen, die sich auf neue Technologien stützen. Man konzentriert sich auf die Sicht des Lernenden und stützt sich auf die Auswertung der in der höheren Schulbildung, Berufs- und Erwachsenenbildung verwendeten Literatur. Es wird die Entwicklung von Richtlinien bei der Anwendung dieser Grundlagen bei bestimmten Lernvorgängen besprochen und die Stärken und Grenzen ihrer Anwendung diskutiert.

\section{Introduction}

The use of the new technologies in university teaching and learning is growing rapidly, with many claims for its increasing impact on the processes and outcomes of teaching and learning. Much of this is occurring in an ad hoc way, driven by the technology itself. Many of the developments adopt a teacher-focused rather than student-focused perspective in the process of translating teaching practices into new forms. They involve designing and presenting materials using new technology rather than utilizing knowledge of how students' experience learning through the technologies. Indeed, a study by Alexander and McKenzie (1998) showed that much of development and evaluation focused on improving students test scores or on improving the productivity of teaching and learning. In their study they found little emphasis on demonstrating an improvement the quality of students' experience using the new technologies, despite the claims often made that new technologies enhance the quality of learning.

The aim of this paper is to contribute to a better understanding of how those designing and using new technologies can usefully examine their own products from the perspective of their impact on learning. It does this by establishing a framework for the appraisal of learning activities derived from our interpretation of current research and scholarship about learning in higher and adult education. While the approach described is focused primarily on designers of technology-based learning programs, it is also relevant to users attempting to integrate a given package into their own teaching activities. It will also become apparent that, although it was not developed with this goal in mind, this approach is also applicable to learning designs that do not involve the use of new technologies.

In this paper we adopt an exclusively learner-focused perspective. We take as our central focus students' experiences of learning using new technologies. Our view is that learning arises from what students experience, not what teachers do or technology does. Following a discussion of the background to the project, we summarize 
outcomes of research in teaching and learning in higher education from the student learning perspective. We then draw upon insights gained from the experience-based learning tradition in adult education to situate the design of a more student focused set of guidelines for appraising uses of new technologies in university teaching and learning. We briefly discuss the way these were developed, show how they can be used and consider their use in improving the quality of products.

The authors developed the framework and guidelines as part of a project funded by the Australian Universities Teaching Committee to guide the development, redevelopment and evaluation of learning designs. ${ }^{1}$ Learning designs refer to a variety of structures using new technologies that support student learning experiences. Learning designs may be at the level of a whole subject, subject component or learning resource. An example of a learning design is:

A situated learning approach for teachers in which they explore a variety of assessment strategies for the K-12 mathematics curriculum. The learning environment comprises a multimedia CD-ROM package that provides five complex and sustained investigations into assessment strategies in mathematics classrooms and ten problems each focusing on a single issue concerning assessment strategies for mathematics. This forms one activity within a subject in a teacher education program.

We set out to develop a framework and to pilot and use a set of guidelines for the formative and summative review and development of learning designs. Our rationale for doing this was that if the outcomes of the use of learning designs is high quality lifelong learning outcomes, not just short term reproduction outcomes, then we needed to develop guidelines which would help those using them to review designs from a learning perspective and to point to areas in which they needed to be changed. That is, identify what features of the learning design would need to be altered to enhance the likelihood of the activity prompting a high quality learning experience on the part of the students engaging with it.

\section{Research on learning in higher and adult education}

When confronted with the challenge to develop the framework we naturally drew on our own background of research and scholarship on teaching and learning and the work that had influenced us most. We had both been immersed in research and development on university teaching over the last 25 to 30 years, though during part of this period one of us (DB) had moved more into the area of adult learning.

This period has seen the development of a substantial body of research into students' and teachers' experiences of teaching and learning in higher education (Marton et al., 1997; Ramsden, 1992; Prosser and Trigwell, 1999; Biggs, 1999). That research has shown that rather than there being a direct connection between the way teachers teach and design their courses and the quality of their students learning outcomes, the relationship is indirect. The way students perceive and understand their learning environment and the way they approach their learning in relationship to these perceptions have been found to be major intervening factors between teachers' teäching and students' learning outcomes.

From this student learning perspective, students in higher education have been shown to approach their learning within the same courses in fundamentally different ways. A surface approach to learning has an intention to reproduce in the short term rather than on understanding in the longer term (Entwistle and Ramsden, 1983; Marton and Säljö, 1976). This fundamental variation in approaches to learning has been shown to be related to the quality of student learning outcomes in a range of disciplines (see Marton and Säljö, 1976, for an early study and Crawford et al., 1998 for an example of a later study).

These approaches to learning have, in turn, been shown to be fundamentally related to how the students perceive their teaching and learning environment - not on how the environment was designed, but how it is experienced (Entwistle and Ramsden, 1983; Trigwell and Prosser, 1991a and 1991b). Student who perceive that the teaching is good and that the aims and goals are clear to them are more likely to be adopting deeper approaches to learning; that is, approaches in which they seek to understand and gain meaning from their study. While those who perceive the workload to be too high and that assessment processes aim at testing reproduction are very likely to be adopting surface approaches; that is, they tend to memorise facts and restrict themselves to what is absolutely required of them.

A fundamental aspect of this research perspective is that it conceptualizes teaching and learning as a relational phenomena, and that learning is always situated in a particular context. That is, students perceive the same learning context in different ways and this variation in ways of perceiving the context is fundamentally related to how they approach their learning and to the quality of their learning outcomes. From this perspective, it is not only important that we design teaching and learning activities to support and encourage deep engagement with 
the subject matter, but more importantly that students perceive and understand that design in ways that support them in adopting deeper approaches to study. Issues that come to the fore in analysing teaching and learning situations from this perspective include:

- how learners perceive and understand the aims and objectives - not how well the aims are stated;

- how they see examples relating to their experience and understanding rather than just how the examples relate to the discipline;

- how they see each aspect of teaching and learning context relating to other aspects of the context - not just how well they do relate;

- how they themselves perceive their readiness in terms of prior knowledge and understanding.

This perspective is, in most ways, consistent with principles that have emerged from experience-based learning perspectives in the field of adult and professional education. For example, Boud et al. (1993) identified five propositions about learning from experience which encapsulate the learning-centred perspectives to be found in that literature. These are:

- Experience is the foundation of, and the stimulus for, learning

All learning builds on what has gone before. A new experience is understood in terms of what is already known. The desire to learn emerges from the experience of the learner either arising from an existing commitment or from the challenge of a new situation.

- Learners actively construct their own experience

Learning is never a passive act. It involves active construction and reconstruction of ideas and experience. Only the trivial or the fragmentary can be learned by rote and even then there can be considerable expenditure of effort on the part of the learner. Learning can be enjoyable and engaging, but only when the learner is substantially involved.

- Learning is a holistic process

Learning, even of academic subjects, is never solely a cognitive endeavour. It involves the emotions and the will. A focus on one to the exclusion of others creates a partial and impoverished experience. Satisfaction derives from engaging as a whole person.

- Learning is socially and culturally constructed

Learning does not occur in isolation. Peers influence it, by social and cultural expectations and by what is accepted by the community as legitimate outcomes. In order to learn we all need interventions from outside ourselves whether these are the direct influence of others or their indirect influence transmitted through learning resources.

- Leaming is influenced by the socio-emotional context in which it occurs

Learning does not occur in isolation and it is not a purely intellectual enterprise. The extent to which we can sustain learning over time is a function of the emotional and personal support we can gain from others. The extent to which we are motivated to learn depends as much on the context of learning as it does on intrinsic interest in the object of study.

From both the student learning in higher education perspective and that of experience-based learning it is clear that it is how learners uniquely experience the teaching and learning situation which is fundamental to the quality of their learning outcomes. A difference of emphasis occurs as a result of the contexts in which these two traditions have developed and the objects of learning which have been studied. Studies in student learning literature are dominated by concerns about learning in disciplinary and professional contexts, in situations in which a body of knowledge is often defined independently of students. In contrast, learning in work, community and personal development contexts has more frequently influenced literature on experience-based learning where codified knowledge is less common.

\section{Development of the framework}

Given this body of knowledge about learning, we considered what might be the implications for learning designs using new technologies. The key implication, of course, is that it is not just how well we design and implement applications of the new technologies, but more importantly how students experience and understand those designs. It is not just how well the new designs are integrated into a course as a whole, but how students experience and understand the particulars of that integration. We need to put ourselves in learners' shoes and try to see our designs from their perspective.

Drawing upon our experience of the ideas and practices outlined above, we went about developing and piloting an approach for developing and improving learning designs. The features of the framework and ways of using the guidelines derived from it were developed through the following process: 
1. A framework was proposed and a draft set of guidelines to operationalize it was developed by the authors in the form of a set of questions.

2. The framework and the questions was piloted by the wider project team on a selection of learning designs.

3. The draft set was revised as a result of discussions based upon the pilot study.

4. The re-drafted guidelines were subjected to a second trial and further revised.

5. The re-redrafted set were then discussed by an international reference group for the project and the ones reproduced here agreed.

The principles we adopted in establishing the framework and qustions were ones of:

- Simplicity - they should not be so complex they become too onerous to use.

- Breadth - they should cover all the major considerations we could identify.

- Utility - they must point to matters which lead to action to improve the quality of learning.

- Accessibility - while the guidelines were underpinned by research and conceptual frameworks, they should be represented in language which could be readily understood.

- Ability to be read at different levels of sophistication - it was necessary for them to make sense from the point of view of both those not familiar with the research literature and concepts as those who were.

This latter point creates a dilemma. A full appreciation of the framework is only possible for those with an understanding of the ideas and concepts on which they are based. There is therefore a risk in portraying them in 'everyday language' that the implications of each are not fully considered. It is impossible, of course, to build into guidelines an entire study program about the concepts they use. It is a reasonable expectation, however, that those who develop learning designs should have a sound appreciation of the ideas and concepts of teaching and learning. The framework therefore represents a précise of these ideas as applicable to a learning design.

In the next section we detail the framework, discuss how it relates to a student-focused perspective, describe the guidelines and how they are intended to be used.

\section{Description and analysis of the framework}

The major themes chosen and the associated elements regard learning as holistic, relational and problematic. The principles are holistic in that they incorporate both learning outcomes and learning processes. They are based upon a view of learning in which it is the students experiences of the processes and outcomes which are the point of departure - not the teachers or designers experiences. They draw both from an individual learning perspective and from an appreciation of the situated and social nature of learning.

Of particular significance is the assumption in this representation that learning is always relational. That is, learning arises through the interactions between a learner and the learning environment and that no environment can be guaranteed to generate learning independent of what the learner brings to the encounter and how the learner perceives the situation. Learning designs represented in software tools and templates can enhance the possibilities of reaching certain learning outcomes but they cannot guarantee it. At least two sets of relationship must be considered: the relationship of the tools to the ways the body of knowledge considered is constructed by the author, and the relationship of both of these through the specific instructional activity to what learners bring to their encounters with it.

The main elements of the framework as originally developed are portrayed diagrammatically in Figure 1. In any given context of learning, some of these principles will be more prominent than others

In using or applying or analysing the principles further, it needs to be born in mind that in any application of them, while any one principle may be foregrounded, it needs to be seen against the background of the other principles. The principles represent a coherent set. All must be considered in any application. All are subject to interpretation and the ways in which they will be manifest in any particular application will be many and varied.

They are not an exhaustive list. They represents key issues arising from our understanding of the literature in higher, adult and professional education. These principles could be elaborated with different emphases and use of terms. However, we have kept in mind the application of these in E-learning in the ways in which we have formulated them.

The guidelines are structured around four key areas, with a number of questions under each. The four key areas are:

1. Engaging leamers. This includes starting from where learners are, taking into account their prior knowledge and their desires and building on their expectations. 


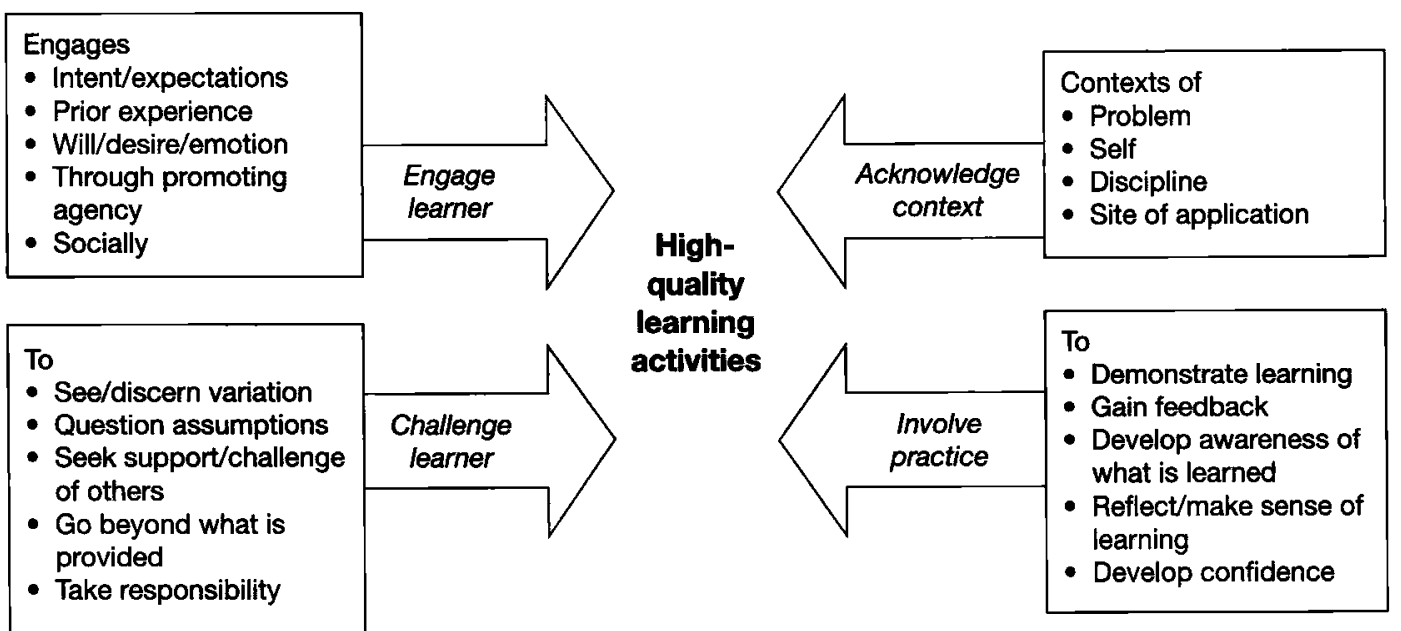

Figure 1 Influences on high quality leaming

2. Acknowledging the leaming context. This includes the context of the learner, the course of which the activity is part and the sites of application of the knowledge being learned.

3. Challenging leamers. This includes seeking to get learners to be active in their participation, using the support and stimulation of other learners, taking a critical approach to the materials and go beyond what is immediately provided.

4. Providing practice. This includes demonstration of what is being learned, gaining feedback, reflection on learning and developing confidence through practice.

These were chosen for reasons of transparency and to account for the fundamental requirements of any learning activity.

The questions relating to each area are shown in Table 1 . They are the result of the three iterations with consultative groups identified earlier.

These four key areas are considered to be fundamental to enhancing the students' experiences of their learning activities - and are of particular concern when considering the use of somewhat decontextualized learning objects. The issue of engaging learners deeply with the material they are studying requires that learning activity be analysed in terms of how it relates to the student prior experiences of studying, how it relates to the learners present goals for learning, and how it engages them affectively and emotionally with the material they are studying. The acknowledgement of the learning context from the learners' perspectives and how the learning activity can be seen from the learner's learning contexts plays a vital role in facilitating high quality learning. Here the analysis needs to consider the sorts of demands that are placed on the learning in their everyday life, how the learning material relate to the context of their lives, and how the overall learning experiences relate to their cultural and social backgrounds.

Table 1 Questions in each of the four key areas

\begin{tabular}{ll}
\hline Key area & Questions \\
\hline $\begin{array}{l}\text { 1. Learner } \\
\text { engagement }\end{array}$ & a. How does the activity identify and build upon learner intents (desires or goals) and \\
& expectations? What assumptions does it make? \\
b. In what ways does the activity take account of learners' prior experience and \\
understanding at each stage (with regard to content, language and terminology, type \\
of task, technology-used, etc.)? \\
c. How does the activity enable students to experience the concepts/ideas/issues of the \\
course in a variety of different ways? (E.g. are different ways of involving students in \\
working with the key concepts of the course used?)
\end{tabular}


Table 1 continued

\begin{tabular}{|c|c|}
\hline Key area & Questions \\
\hline & $\begin{array}{l}\text { d. What variety of opportunities does the activity provide for students to engage with } \\
\text { their peers and gain feedback from them? Are activities with peers developed } \\
\text { throughout the activity? } \\
\text { e. How does the formal assessment for the activity facilitate or inhibit student } \\
\text { engagement? } \\
\text { f. In what ways does the activity enable learners to reflect on their experience and } \\
\text { integrate and consolidate the various parts of the activity? } \\
\text { g. How does the activity engage students affectively (with regard to feelings and } \\
\text { emotions) and link with them personally? How inviting is the activity? } \\
\text { h. What mechanisms are available to give students a sense of control over their } \\
\text { engagement with the activity? For example, through identifying what they need to } \\
\text { learn and influencing what they do? }\end{array}$ \\
\hline
\end{tabular}

2. Acknowledge the learning context

3. Challenge learners

4. Provide practice a. In what ways are problems issues and activities presented fully in the

i. Specific context of the field of study/professional practice?

ii. Broader context of the social/political/economic/environmental (etc.) circumstances as appropriate?

b. How does the activity take account of the current circumstances of the student (e.g. task demands, resources available)?

c. How does the activity take account of the place of application of what is being learned (e.g. through focusing learners on their current workplace, their anticipated professional activity, or in application to particular aspects of their academic subjects)?

d. How does the activity help students to see how the current learning can be used/built upon in various contexts and situations beyond the ones given?

e. How are the knowledge demands (level of difficulty, knowledge assumed, etc.) of the activity identified and students equipped to deal with them?

f. What cultural assumptions are built in to the activity? Are stereotypes avoided? What are the limits to where this activity is appropriately used (e.g. only to be used with students familiar with dominant Australian cultures)?

g. How do student assessment activities match learning outcomes and provide expression for appropriate high-level quality outcomes?

a. How are students involved in questioning the knowledge and experience they bring to the activity?

b. How do students become aware of the limits of the knowledge they develop through the activity?

c. How does the activity assist students in going beyond the knowledge/resources provided for them? Is this done in ways that are realistic for students to pursue?

d. In what ways does the activity aid and equip students to make decisions about significant aspects of planning, directing and assessing their own learning in subsequent activities?

e. How are students encouraged to be self-critical and test their own assumptions at various points?

a. How does the activity encourage and allow students to articulate and demonstrate to themselves and others what they are learning?

b. In what ways is appropriate feedback (in terms of sources, nature and timing) available at key points in the learning process?

c. How does the activity help and equip students to discern and apply standards and criteria that indicate they are learning appropriately?

d. Are learners exposed to and work with models of the kinds of practice expected of them? (i.e. do the activities enable them to experience good examples of work of the types they are expected to produce?) 
If we are to engage learners meaningfully with the material they are studying, learners need to experience a challenge and respond to it, not just be the recipient of an information transfer. The learning experience needs to challenge the learners experiences of the world, the learners present understandings, and help them develop their self-critical skills. Finally, the provision of authentic practice helps students demonstrate their learning changes understandings, helps them better appreciate the criteria and standards being applied to their learning, develops their confidence and assists them experience a coherence between aims and goals, learning tasks and assessment of outcomes.

Some of the questions within each of the four areas could be included in areas other than in the ones in which we placed them. Others could be readily reworded in different ways. The final set of items is not intended to be definitive, but illustrative of important considerations to be taken into account in making judgements about technology-based learning activities. It should be noted that none of them is unique to a technology-rich environment, they could just as easily be applied to any activity designed to foster learning. This is as it should be: technology exists to enhance the achievement of educational goals, it is not an end in itself.

After completing the development of the framework and guidelines we were gratified to find how closely our views aligned with the principles outlined by Hung and Chen (2001) for web-based E-learning drawing upon a situated cognition and Vygotskian perspective. Their key principles were that:

- Learning is embedded in rich cultural and social contexts

- Learning is reflective and metacognitive

- Learning is an identity formation or act of membership

- Learning is a social act/construction mediated between social beings through language, signs, genres and tools

- Learning is socially distributed between persons and tools

- Learning is demand driven - dependent on engagement in practice

(Hung and Cheng, 2001, p. 8)

While we have developed our framework from different bodies of research, the convergence of principles from different traditions provides encouragement that there is a secure foundation available from which to view the development of technologies for leaning.

\section{How the framework can be used}

It emerged at a very early stage of development that it was impossible to make judgements about the impact on learning of any particular learning design or product independent of the context and way in which it was being used. Statements which can be made about learning on the basis of a generic design, without knowledge of the settings in which it would be used, the kinds of learners that would be involved and the particular outcomes which were being sought are so limited that they provide no useful basis for redesign and improvement. It was therefore necessary to apply the guidelines to products as used in real contexts.

In the full documentation of the framework and guidelines, each key area is presented as a question followed by a list of sub-questions on a single page. Users are invited to take a particular example of a learning activity in the context in which it is used. They then spend an extended period of time interacting with it and inspecting as much data about student use and the context in which it is deployed as possible. They write a rich description of the features of the product they are examining in terms of the extent to which it addresses the points raised in the subquestions. They then summarize how the technology used enhances or inhibits these features.

A key feature of the use of the guidelines is the addressing of final two question. They are:

- List the key design features of the activity most important in making it work effectively. (These may or may not be technology-related.)

- What features would need to be changed or added to the activity to make it more effective in enhancing learning?

Having carefully examined the learning activity from the perspective of the previous questions, the analyst is asked to list the key design features of the activity and to indicate how the activity could be changed or what additions need to be made to increase its effectiveness as a learning experience. At this stage the analyst should not just be focusing on the technical or instructional design of the activity, but how that activity is likely to be experienced by students in real teaching and learning situations. In such a context it may well be that the recommended addition is more in terms of suggestions to the user on how the activity may be integrated into a particular course. Or, alternatively, suggestions about other aspects of the course which need to be put in place to ensure that this activity is productive. 


\section{Discussion and conclusion}

In developing, piloting and using the framework a number of issues emerged. The first is the tension in bringing together two areas of research and development - instructional design and student learning research. Both areas have developed relatively independently of each other. The instructional design literature focuses on how the learning design should be created to support student learning. The student learning literature focuses on how particular learning situations are situated in whole programs and how students perceive and understand the requirements on them. Each complements the other. But bringing them together is not an easy task. There is a different set of terminologies used in each area as well as a different perspective. The important aspect of this project was to develop guidelines incorporating key aspects of a student-focused perspective but situated in a language and context that was comprehensible and usable by instructional designers. We believe that through the pilot studies and the subsequent discussions and revisions we have made a good start on this process.

A second issue, related to the first, was the need from a student learning perspective to examine the use of the learning design in the context of a course as a whole. Can robust learning designs be created independent of the context in which they are to be used? Our view is that at one level they cannot, but at another they must be independent if every designer is not to face the prospect of starting completely afresh each time a new course is created. However, the key question is: which features of the context are salient and must be taken into account in the basic learning design and which can be open for adaptation in the micro-context of application?

The present enthusiasm for E-learning and the assumption that it can reduce costs is based upon the premise that by and large learning designs can be context independent. From our point of view, this is over-optimistic. There is a much greater variation among learners in the ways they experience an activity and a greater variation in the contexts in which learning activities are experienced that can justify this premise. This is not to imply that robust learning designs cannot be developed, but that they may be more limited in scope than is often expected, and the development effort required to produce them may be uneconomic for most educational institutions.

\section{Note}

1. Project titled 'Information and Communication Technologies and their Role in Flexible Learning' led by Ron Oliver from Edith Cowan University and Barry Harper from the University of Wollongong

\section{References}

Alexander, S and McKenzie, J (1998) An Evaluation of Information Technology Projects in Australian Higher Education, Australian Government Publishing Services, Canberra.

Biggs, JB (1999) Teaching for Quality Learning at University, SRHE and the Open University Press, Buckingham.

Boud, D, Cohen, R and Walker, D (1993) Understanding learning from experience. In Boud, D, Cohen, R and Walker, D (eds) Using Experience for Leaming (pp.1-17), SRHE and Open University Press, Buckingham.

Crawford, K, Grordon, S, Nicholas, J and Prosser, M (1998) Qualitatively different experiences of learning mathematics at university, Learning and Instruction, 8, 455-68.

Entwistle, $\mathbf{N}$ and Ramsden, P (1983) Understanding Student Leaming, Croom Helm, London.

Hung, D and Chen, D (2001) Situated cognition, vygotskian thought and learning communities of practice perspective: implications for the design of web-based E-Learning, Educational Media International, 38, 1, 3-12.

Marton, F and Säljö, R (1976) On qualitative differences in learning. I. Outcome and process, British Joumal of Educational Psychology, 46, 4-11.

Marton, F, Hounsell, D and Entwistle, NJ (eds) (1997) The Experience of Learning: Implications for Teaching and Studying in Higher Education, 2nd edn, Scottish Academic Press, Edinburgh.

Prosser, M and Trigwell, K (1999) Understanding Leaming and Teaching: The Experience in Higher Education, SRHE and the Open University Press, Buckingham.

Ramsden, P (1992) Learning to Teach in Higher Education, Routledge, London.

Trigwell, K and Prosser, M (1991a) Relating approaches to study and the quality of learning outcomes at the course level, British Joumal of Educational Psychology, 61, 265-75.

Trigwell, $\mathrm{K}$ and Prosser, $\mathrm{M}$ (1991b) Relating learning approaches, perceptions of context and learning outcomes, Higher Education, 22, 251-66. 


\section{Biographical notes}

David Boud is Professor of Adult Education and Associate Dean (Research and Development) in the Faculty of Education at the University of Technology, Sydney. He has written extensively on teaching, learning and assessment in higher, professional and adult education, has is been President of the Higher Education Research and Development Society of Australasia (HERDSA) and is co-editor of the journal Studies in Continuing Education. His most recent books (written or edited with various others) are Working with Experience: Animating Learning, Understanding Leaming at Work (both Routledge), Work-Based Leaming: A New Higher Education? (SRHE/Open University Press) and Peer Leaming in Higher Education: Leaming With and From Each Other (Kogan Page). In recent years he has developed an interest in E-learning and he has been part of the core team which established a Masters in Adult Learning and Global Change, a web-based course between four universities on four different continents.

Michael Prosser is Associate Professor and Director of the Institute for Teaching and Learning at the University of Sydney. He has published widely on teaching and learning in higher education. He was, for many years, a co-editor of the journal Higher Education Research and Development. Much of his research and previous publications have been summarized in a recent book, co-written with Keith Trigwell, Understanding Learning and Teaching (SRHE/Open University Press).

\section{Address for correspondence}

David Boud, Faculty of Education, University of Technology, Sydney, PO Box 123, Broadway, NSW 2007, Australia; e-mail: David.Boud@uts.edu.au

Michael Prosser, Institute for Teaching and Learning, University of Sydney, NSW 2007, Australia; e-mail: m.prosser@itl.usyd.edu:au 


\section{EDUCATIONAL}

\section{MED I A}

\section{INTERNATIONAL}

EMI

EMI

EMI
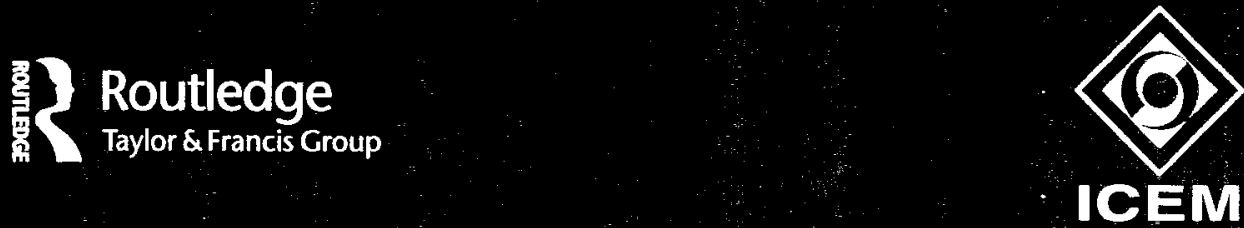

The Official Quarterly Journal of the International Council for Educational Media 


\section{Contents}

\section{John G Hedberg Editorial}

H. Atan, F. Sulaiman, Z. A. Rahman and R. M. Idrus Gender Differences in Arailability, Intemet Access and Rate of $L$ sage of Computers among Distance Education Leamers

Drew Tiene Addressing the Global Digital Diride and its Impact on Educational Opportunity

Jane M. Garey, Ines M. Chisholm and Leslie H. Irwin The Impact of Access on Perceptions and Attitudes Toucards Computers: An International Study:

David Boud and Michael Prosser Appraising . lize Technologies for Learning: A Frameitork for Derelopment

Hung W.L. David and Chen D.-T. Victor Learning zithin the Context of Communities of Practices: A Re-Conceptualization of Tools, Rules and Roles of the Actirity System

Yu-Mei Wang From Teacher-centredness to Student-centredness: Are Preservice Teachers Making the Conceptual Shift II Then Teaching in Information Age Classrooms.?

Mandi Axmann, Wiida Fourie and William Duncan Paop Adding let Value: The vature of Online Education at a South African Residential Institution

Amy C. Bradshaw, Jeanne L. Bishop, Linda S. Gens, Sharla L. Miller and Martha A. Rogers The Relationship of the World IVide IV eb to Thinking Skills

K. Vryzas and M. Tsitouridou Children and Computers: Greek Parents' Expectations

Shiao-Chuan Kung Factors that Affect Students' Decision to Take Distance Leaming Courses: A Survey Study of Technical College Students in Taizian

Peter Hillis Multi-Media and Histony Education: A Partnership to Enhance Teaching and Learning

Arnauld Séjourné Concepts of Hypermedia in Physics: The Importance of Resources from the Point of Viezi' of Leaming

Lynette Stockhausen and Graig Zimitat lext Leaming: Re-apprenticing the leamer

Avi Cohen and Stephen Heppell 'Toung" is . Vol. Vecessarily an Isue of Age

Book reviews
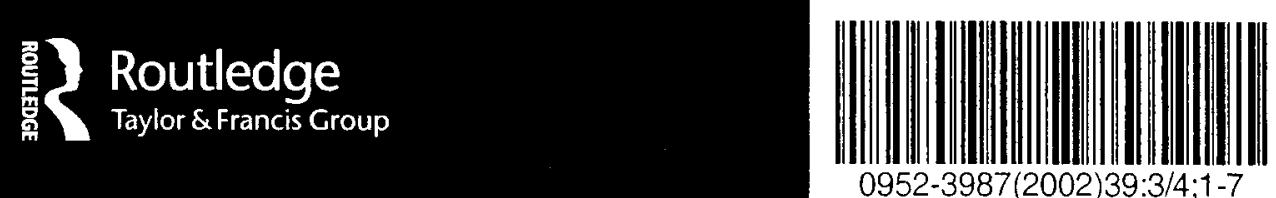

The Official Quarterly Journal of the International Council for Educational Media 


\section{Editorial}

Educational Media International has been receiving a substantial increase in papers submitted for review. This issue consists entirely of peer-reviewed papers. We have tried to include papers from different parts of the world to provide a record of how different countries have taken to the use of technologies for learning. We have also seen a growth in papers from areas not previously represented in the list of authors in $E M I$ and for this we are very happy that the journal can produce a meeting place and exchange of different pedagogical practices.

This issue will be arriving as the annual conference of ICEM-CIME will be held in Grenada, Spain. It is to be hoped that this gathering will become the focus of the next few issues and the excitement and collaboration will be shared with our readers beyond the conference. $E M I$ has grown over the past few years into a journal that is increasingly accessed online as well as in hard copy. In the past year, we have had in excess of 2,000 individual articles accessed through the online journal system. So while we are both in print and online we hope that the messages contained in these articles will prove useful both in their immediacy and their reflection about lessons learned over time.

John G Hedberg

Professor of Education, University of Wollongong

EMI Editor-in-Chief

\section{Next issue}

Computer mediated communications 